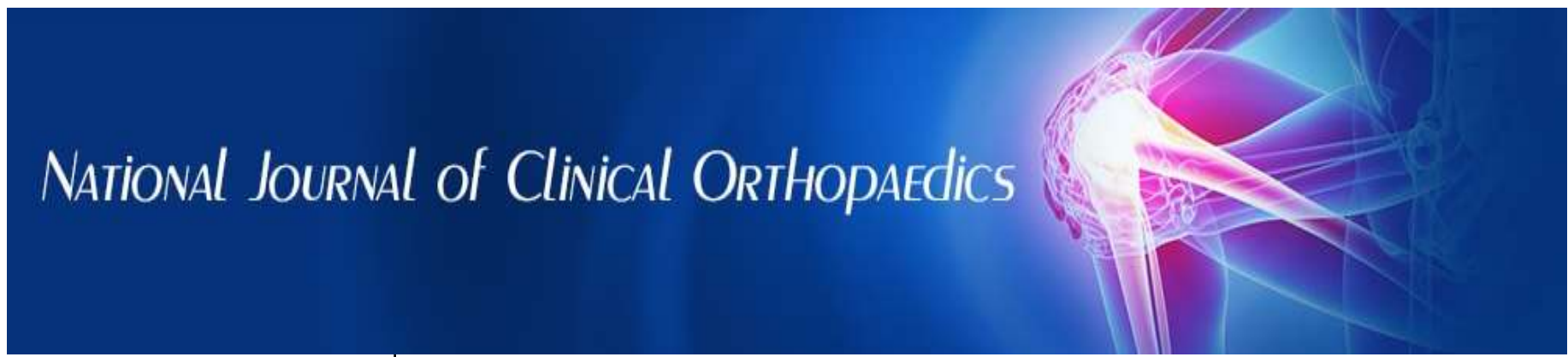

ISSN (P): 2521-3466

ISSN (E): 2521-3474

(C) Clinical Orthopaedics

www.orthoresearchjournal.com

2021; 5(4): 19-23

Received: 13-07-2021

Accepted: 19-09-2021

Dr. Ameer Mohammad Muslem High Diploma Orthopaedic

Surgery, Karbala Health

Directorate, Iraq

Dr. Mohammed Naser Hussein High Diploma Orthopaedic Surgery, Karbala Health

Directorate, Iraq

Dr. Abdulkareem Qasim Hussein High Diploma Orthopaedic Surgery, Karbala Health

Directorate, Iraq
Corresponding Author: Dr. Ameer Mohammad Muslem High Diploma Orthopaedic Surgery, Karbala Health Directorate, Iraq

\section{Faulty external fixation}

\section{Dr. Ameer Mohammad Muslem, Dr. Mohammed Naser Hussein and Dr. Abdulkareem Qasim Hussein}

\author{
DOI: https://doi.org/10.33545/orthor.2021.v5.i4a.321
}

\section{Abstract}

External fixation a common method for treatment of open fractures with different degrees caused by many mechanisms. It is very vital in case of stabilization of fractures of poly-traumatized patients. Perfection in the fixation and good stability of the fixator will affect the outcome of treatment and induce early fracture healing. Faulty external fixation is a common problem in our locality. The aim of our study is to discover and categorize the faulty fixation and try to know the reasons behind these faults and what is best way to overcome it. We randomly studied (212) external fixators, 168 (79\%) patients and 44 (21\%) x-rays. These (168) patients were, 163 (97\%) males and 5 (3\%) females aged from (5-56) years and have been treated in many hospitals during the period from the $5^{\text {th }}$ of October 2014 till the $10^{\text {th }}$ of November 2015. (85\%) of the patients that were treated by external fixation were due to military and mass casualties' injuries. (1145) pins distributed on (212) fixators were studied. X-rays of the fracture and the external fixation site have been taken and carefully examined. We found that 350 pins $(35 \%)$ were over penetrated to the far cortex, 112 pins $(9.7 \%)$ in the fracture, 45 pins $(3.9 \%)$ just anchored in near cortex, $16(1.3 \%)$ broken pins and 9 pins $(0.7 \%)$ in the joint. Regarding the faults of the fixator as whole, we found that 33 fixators (15.6\%) with pins far away from the fracture line, 88 fixators (41.5\%) with pins not ideally separated on each segment of the fracture, 15 fixators $(7.1 \%)$ with insufficient number of pins, 4 fixators $(1.9 \%)$ with wrong decision for fixation, 7 fixators $(3.3 \%)$ with wrong site for pin insertion. We discovered that 131 fixators $(61.8 \%)$ were applied without accepted anatomical reduction to the fractured bone. As a final result of the (212) fixators we studied, there were (199) faulty external fixators which accounted for $(94 \%)$. We concluded that the faulty external fixation in our locality is much more than what we expect. Lack of full awareness about the AO principles of external fixation is the main reason beyond this high rate of faulty fixation.

Keywords: External, fixation, fracture

\section{Introduction}

External fixation is a very common method in treating open fractures ${ }^{[1]}$. It is not rather a new method. It had been used since the days of Hippocrates ${ }^{[2]}$ who was the first to describe the use of external fixation in treating fracture of the leg. The development chain of the external fixator continue for progress. Malgaigne $1840^{[3]}$ from the recent history was the first to use pins with the fixator. Many great inventors gave their touches to that device; Parkhill $1894{ }^{[4]}$, Lambotte $1902^{[5]}$, Stader $1937^{[6]}$, Hoffmann $1938^{[7]}$ and Ilzarov $1950^{[8]}$. The Association for Study of Internal Fixation AO/ASIF recommended the use of external fixation and produced its mono-lateral external fixation system, which is widely, used especially for the damage control orthopaedic. External fixation is a good option in treatment of many types trauma like bone loss, sever tissue injury, fractures with vascular injury, pelvis fracture, infected fractures and septic arthritis ${ }^{[9]}$. Different types of external fixators were made. Generally, they are of two groups: pin and ring fixators. The pin external fixator, which has very popular use, consists of four main components ${ }^{[10]}$ : tube, Steinmann pins, Schanz screws and the adjustable clamps. The schanz screws anchored to the bone around the fracture site and attached to the bar outside the skin through the adjustable clamps. The construct allows for easy reduction of the fracture. The technique of pin insertion to the bone has a great effect on the stability of the fixator. The heat produced during the drilling of the bone my lead to damage of the bone around the pinhole ${ }^{[11]}$. Many factors affects the stability of the fixator which is important in case of fracture healing ${ }^{[12,13]}$ : number of pins, separation of pins on each segment of the 
fracture, number of bars, separation of the bars, distance between the bar and the bone, number of planes for pin insertion and pin diameter. The pins of the fixators must be inserted in safe anatomical corridors to insure safety to vital structures like nerves and blood vessels ${ }^{[14]}$. Any disturbance in the stability and faults in the insertion techniques of the external skeletal system will lead to faulty fixation. Possible reasons that produce faulty external fixation are: pin in the joint or fracture site, pins either over penetrated the far cortex or just in the near cortex, pins far from the fracture line, pins not separated on each segment of the fracture, insufficient numbers of pins of the fixator, wrong site for pin insertion or external fixation to the fracture without accepted anatomical reduction.

\section{Patients and methods}

This is a pilot study was done on two groups of materials. The first group are patients admitted or visited the orthopaedic wards in Basra General Hospital and Ibn Albaytar Private Hospital in Basra City, Ghazi AL-Hariri Hospital for Surgical Specialties and Al-Kadhimiya Teaching Hospital in Baghdad and AlHussain Hospital in Karbala during the period from the $5^{\text {th }}$ of October 2014 till the $10^{\text {th }}$ of November 2015.

Inclusion criteria:

1. Patients had trauma and was admitted to the previous hospitals and treated by external fixation.

2. Referred patients from other hospitals whom were treated previously by external fixation.

3. X-rays films of fractured bones that was previously fixed by external fixation (the patients are not available and some demographic information missed) collected from my teachers and colleagues.

\section{Exclusion criteria}

We did not exclude any patient treated with external fixation device.

A history was taken from the patients including age, sex, the time of injury, time of fixation and the type of injury whether open or closed. The cause of the injury or condition that was treated by external fixator was recorded like blast, bullet or car accident and other mechanisms. X-ray films were taken to the site of the trauma that was fixed by external fixation. The type of external skeletal fixation system (AO device, Hoffman or others) was recorded. All the components of the external fixator were documented like bars and schanz pins. We studied each pin individually to know the type of fault that was caused by that individual pin. We studied the construct as whole whether it is stable or not based on the AO principles of fracture management $[12,13]$. The other group of the materials in this study was the $\mathrm{X}$ rays. The demographic data are missed for these $\mathrm{x}$-rays like age, sex, mechanism of injury and surgery timing (emergency or elective). These $\mathrm{x}$-rays was digitally photographed on the $\mathrm{x}$-ray viewer by digital camera. Other x-rays were taken from the computed radiography device monitor (CR) by digital camera. Each case was individually examined and parameters was recorded and results obtained by using the SPSS ${ }^{\circledR}$ IBM version 22.

\section{Results}

According to our inclusion/exclusion criteria 212 external fixators were studied, $168(79 \%)$ patients and 44 (21\%) x-rays. These (168) patients were, $163(97 \%)$ males and $5(3 \%)$ females (figure 28). The age of the patients was ranged from (5) years to (56) years. The range interval was (51) years with mean equal to (28.71), the median equal (28.00) and the Std. Deviation equal to (7.321). We found in this study that the most common age group of patients treated by external fixation was between (2130) years. According to our sample (168 patients) in this study, we found that the most common reason beyond the condition that was treated by external fixation is the blast injury (43.5\%) and the second one is the injury by gun bullets $(41.7 \%)$ as shown in table (1). Regarding the types of the external fixator which had been used in the treatment of different conditions in our study, we summarized it in figure (1).

Table 1: The causes that was treated with external fixation

\begin{tabular}{|c|c|c|}
\hline Causes beyond fixation & Patient no. & Percentage \% \\
\hline bullet & 70 & 41.7 \\
\hline blast & 73 & 43.5 \\
\hline RTA & 17 & 10.1 \\
\hline bone lengthening & 1 & 0.6 \\
\hline machine & 2 & 1.2 \\
\hline FFH & 5 & 3.0 \\
\hline Total & 168 & 100.0 \\
\hline
\end{tabular}

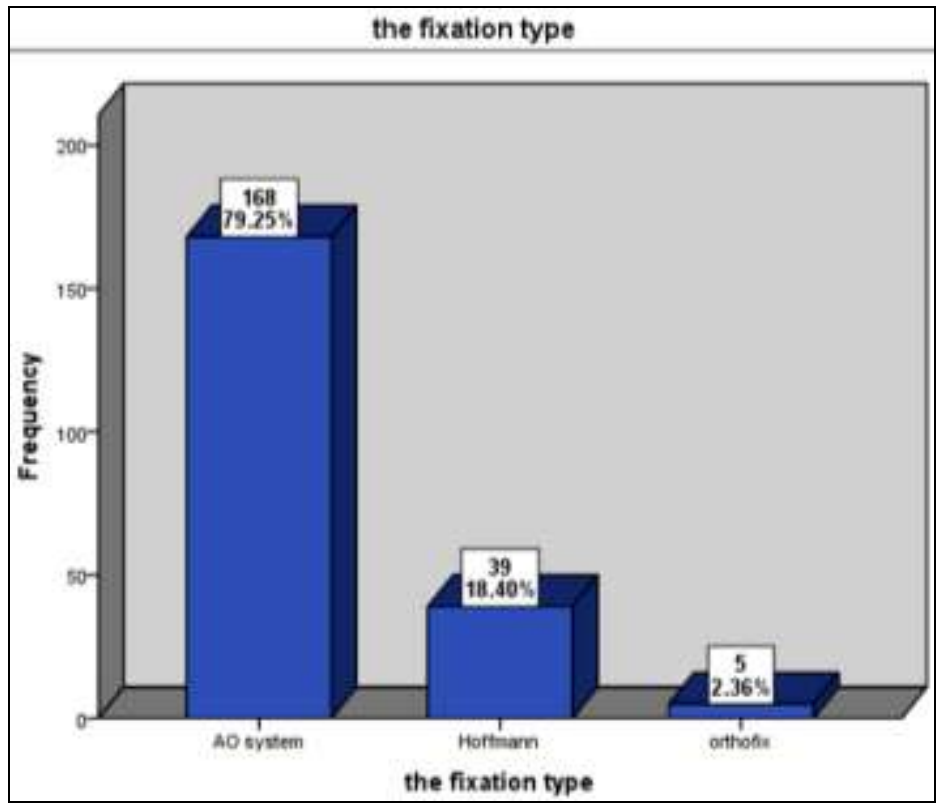

Fig 1: The count and percentage of external fixators in our study 
We found in this study that the tibia is the most common site that the external fixators was fixed to it (79 tibiae). The second site was the femur ( 66 femurs) and the third site for fixation was the knee spanning (19knees). On the other hand, the femur and tibia bones took the first place regarding fracture site $(85$ femora and 84 tibiae) which accounted for about (40\%) for each. According to the time of the surgery for fixation of the (168) patients, we grouped them in to emergency surgery that done within less than 5 days from the time of injury and elective surgery that done after more than two weeks as shown in table (2).

Table 2: Percentage of the timing of surgery

\begin{tabular}{|c|c|c|}
\hline Time of surgery & Frequency & Percentage \\
\hline emergency & 150 & $89.3 \%$ \\
\hline elective & 18 & $10.7 \%$ \\
\hline
\end{tabular}

According to our sample of materials which is (212) external fixators, we found that there are (1145) pins distributed on these fixators. We studied each schanz pin individually and record the fault that caused by that individual pin.

We found that there are faults caused by that individual pin like:

1. Too much penetration of the pin to the far cortex.

2. Pin inside the fracture site if there is no available segment for anchoring.

3. Pin inside the joint.

4. Pin anchored just to one cortex.

5. Broken pins for any reason.

Also, we found that there are faults caused by a group of pins that the external fixator consists of and affect the construct of that fixator as whole like:

1. Proximity of the pins from the fracture site whether near or far.

2. Insufficient number of pins of the fixator according to the bone attached to it.

3. Separation of the pins on each segment of the fractured bone.

4. Wrong or inappropriate decision for using external fixation.

5. Wrong site for pin insertion (not safe anatomical corridors).

6. If there is reduction to the fractured bone or not.

Some of the individual pins produce more than one fault like pin in the fracture site and protruded too much from the far cortex. In addition to that, the group of pins that consisting the external fixator may carry more than one fault like the pins not separated from each other's on the fracture segment on a wrong site for pin insertion and the bone not anatomically reduced, tables $(3,4)$.

Table 3: The counts and percentage of faulty pins of external fixators in this study

\begin{tabular}{|c|c|c|}
\hline Faults of the pins & No. of pins & percentage \\
\hline Too much penetration to the far cortex & 350 & $30.5 \%$ \\
\hline Pin in the fracture & 112 & $9.7 \%$ \\
\hline Pin in one cortex & 45 & $3.9 \%$ \\
\hline Pin in the joint & 9 & $0.7 \%$ \\
\hline Broken pins & 16 & $1.3 \%$ \\
\hline
\end{tabular}

Table 4: The count and percentage of the faults of the fixator as whole

\begin{tabular}{|c|c|c|}
\hline Faulty cause & Number of fixators & percentage \\
\hline Pins far away from the fracture line & 33 & $15.6 \%$ \\
\hline No pins separation & 88 & $41.5 \%$ \\
\hline Insufficient number of pins & 15 & $7.1 \%$ \\
\hline Wrong decision for fixation & 4 & $1.9 \%$ \\
\hline Wrong site for pin insertion & 7 & $3.3 \%$ \\
\hline No accepted reduction & 131 & $61.8 \%$ \\
\hline
\end{tabular}

As a final results of the whole faults of the external fixators in this study which are (212) external skeletal fixators whether the faults is due to the pins in that fixator or due to the faults of the whole construct, we found that there are (199) faulty external skeletal fixators which accounted for about (94\%) as shown in figure (2).

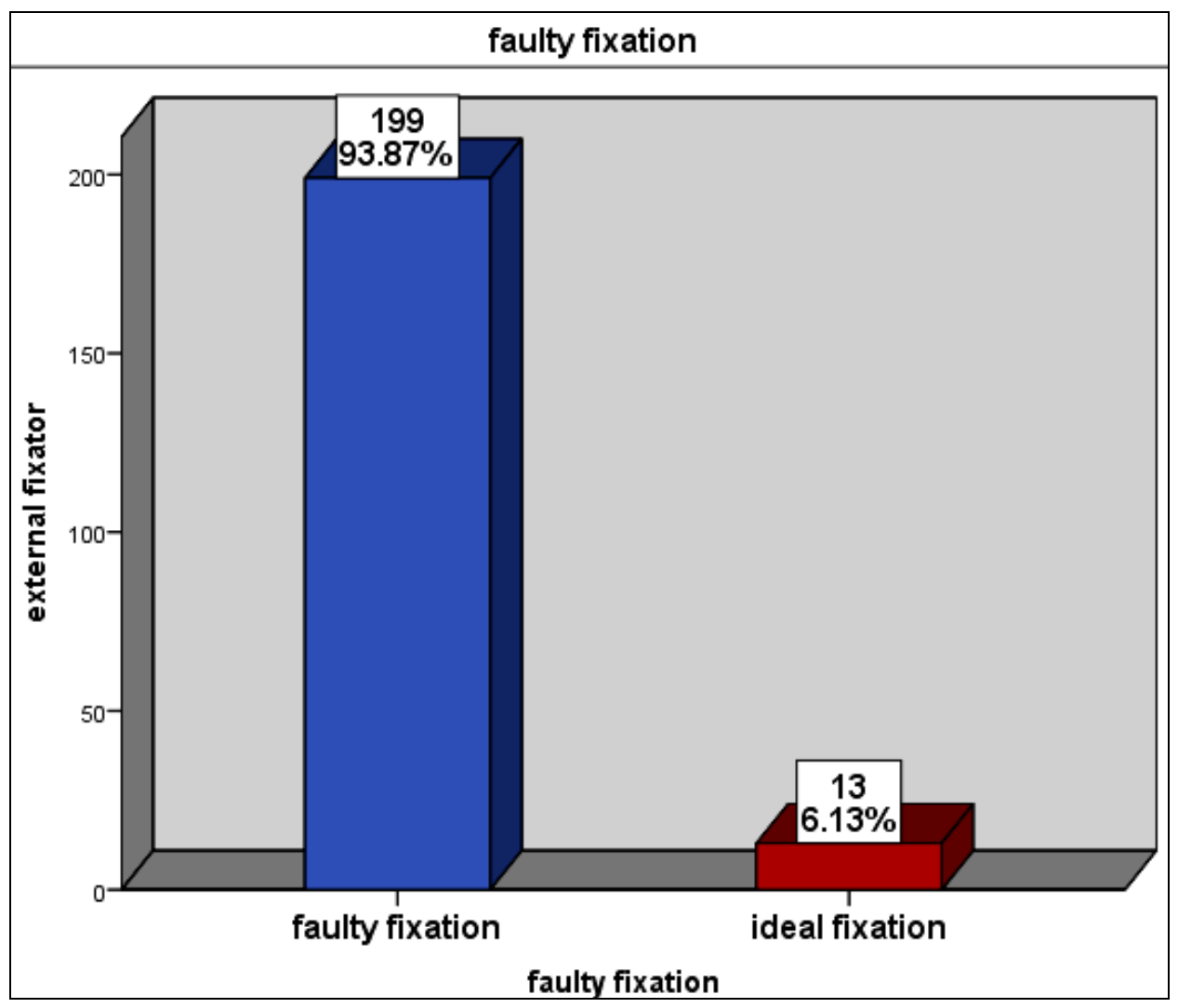

Fig 2: The count and percentage of the faulty external fixators in this study 


\section{Discussion}

External fixation is one of the commonest procedures that used in orthopaedic for treating fractures. It is widely used in the treatment of open fractures especially those caused by missiles [15]. In our locality, due to the consequent wars and military operations especially in the last decade, the use of external skeletal fixation became so widely used. This wide using supposed us to think carefully about the outcomes of our job for the benefit of our patients. It is not allowed to revise the site of surgery because of forgetting or missing part of the surgical steps required ${ }^{[16]}$. Vidal et al. ${ }^{[17]}$ believed that the complications of external fixation are due to faulty techniques or wrong indications. They advised to insert the pins under direct vision, thus avoiding injury to the nerves and vessels. According to our results regarding the reasons beyond treating fracture with external fixation, about $85 \%$ of the patients were injured by projectiles such as bullets, mines, shells and blasts. Most of them are treated in mass casualties' situations based on undocumented information from the medical centers that treated those patients. This leads us to believe that we are dealing with war trauma. Dubravko H. et al. ${ }^{[18]}$ and Labeeu F. et al. ${ }^{[15]}$ reported high complication rates of external fixation used in treatment of military injuries. Although the high rates of complications, Has B. et al. ${ }^{[19]}$ concluded that external fixation is the method of choice for the treatment of open fractures caused by explosive devices. They mentioned that the use of this method in combination with skilful operative technique and proper external fixator selection gives the best result of external fixation. Based on Has B. et al. ${ }^{[19]}$ results and what Hamdan ${ }^{[16]}$ said about the halfway treatment, no excuse will be available to do ideal external fixation even in mass casualties' situations. Sakorafas G. et al. ${ }^{[20]}$ advised that appropriate education is required for surgeons facing military trauma to achieve success in their mission. In our study, $70(41.7 \%)$ patients injured by bullets, 73 $(43.5 \%)$ patients by blasts, $17(10.1 \%)$ patients injured due to RTA, $2(1.2 \%)$ patients injured by machines, $5(3 \%)$ patients injured due to falling from a height. we found that there is no correlation between the mechanism of injury and faulty fixation ( $\mathrm{p}$ value not significant) even in non-military injuries. Regarding the timing of surgery of 168 patients in our study, $150(89.3 \%)$ patients had urgent fixation and $18(10.7 \%)$ patients had elective surgery of fixation. we found that there is no correlation between the time of surgery (emergency, elective) and faulty fixation ( $p$ value not significant). On the other hand, different types of fixators we studied were faulty. We found that $168(79.2 \%)$ fixators were $\mathrm{AO}, 39(18.4 \%)$ were Hoffmann and $5(2.4 \%)$ were orthofix fixators. No relation between the type of fixator and faulty fixation could be seen. This gives us a clue that improper pre-operative planning regarding instruments and expertise are responsible for that high rate of faults. Our opinion go hand in hand with what Giotakis N. et al. had found ${ }^{[21]}$. They also mentioned that "instructional courses on fracture management focus on internal stabilization, leaving external fixation and non-operative strategies as minor inclusions. Consequently orthopaedic trainees are trained towards proficiency with internal fixation methods, and have only a superficial knowledge of external fixation". Topp et al. ${ }^{[22]}$ in 2003 did a cadaveric study to illustrate the incidence of neurovascular injury during external fixator placement without radiographic assistance for lower extremity diaphyseal fractures. In their study, orthopaedic surgeons, with varying experience, externally stabilized 20 fractured cadaver femora and tibiae, 194 half-pins were placed without radiographic assistance. They found that 49\% (95 of the 194 have pins) were over penetrated the far cortex (greater than two threads out the far cortex).This results explain what we had found regarding the faults with pin placement to some extent; $350(30.5 \%)$ out of 1145 over penetrated the far cortex, 112 pins $(9.7 \%)$ in the fracture, 45 pins (3.9\%) just anchored in near cortex and 9 pins $(0.7 \%)$ in the joint. their study also demonstrates that increased experience with standard fixation correlates to safer pin placement feelplaced fixation. In austere conditions, experienced surgeons can safely place external fixators without radiographic guidance. They urge to do pin placement with the fluoroscope assistance. This opinion goes with what Coupland R. ${ }^{[23]}$ found: "The good results that are potentially achievable with external fixation require higher levels of skill of both surgeon and operating theatre nurse. It is only safe in good hands". Ronin G. et al. ${ }^{[24]}$ mentioned that external fixation gives good results if the techniques are applied exactly as described by AO without trying short cuts. Clasper $\mathbf{J}$ et al. ${ }^{[25]}$ reported that $(87 \%)$ of fixators (15 fixators) applied in the field hospital of British Army during the gulf war 2003 required early revision or removal due to complications of the injury or the fixator. They attributed that the early revision is due to the injury severity and frame design. If compared to what we had found, $199(94 \%)$ fixators out of 212 are regarded as faulty fixators. In our study, $81(38 \%)$ out of 212 case had accepted reduction of the fracture, while $131(62 \%)$ case were without accepted anatomical reduction. Strong relation (significant $\mathrm{p}$ value) was found between fracture reduction and faulty external fixation. Unfortunately, no available data about the counts and types of faults regarding external fixation especially those who related to the faulty techniques. Many papers reported the final outcome of the fixation and the possible complications like pin tract infection. Many authors who wrote thoroughly about external fixation recommended the insertion of the pins under image fluoroscopy for perfect construct and fracture reduction ${ }^{[26,27]}$.

\section{Conclusions}

1. The faulty external fixation rate is higher than what we were thought ranging between the faults in schanz pin placement to the faults in the whole construct.

2. Technical errors did by surgeons are beyond this high rate of faults.

3. This technical errors related directly to improper practice of some surgeons regard the ideal construct of the external fixation.

\section{References}

1. Nayagam S, Warwick D. Orthopaedic operations, in: Apley's System of Orthopaedics and Fractures, 9th edition 2010, 361.

2. Apley AG, Noordeen MH. A History of External Fixation. In: Orthofix External Fixation in Trauma and Orthopaedics. Springer-Verlag London Limited 2000, 3.

3. Nelson DL. External Fixation for Distal Radius Fractures. Presented at ASSH Upper Extremity Injuries, San Francisco, CA 2001.

4. Parkhill C. Further observations regarding the use of the bone clamp in ununited fractures, fractures with malunion and recent fractures with tendency to displacement. Ann Surg 1898;27:553-570.

5. Leonard F. Peltier. Fractures: A History and Iconography of Their Treatment. Norman Publishing, 1990, 186.

6. Timothy D Bunker, Christopher L Colton, John K Webb. Frontiers in Fracture Management. Aspen Publishers, 1989, 152.

7. William R Pontarelli. External fixation of the tibial fractures. 
Iowa Orthop J 1982;2:80.

8. Ilizarov S. The Ilizarov Method: History and Scope. In limb lengthening and reconstruction surgery. Informa Healthcare USA, Inc. 2007, 3-5.

9. Hierholzer G, Ruedi TH, Allgower M, Schatzker J. eds. Manual on the AO/ASIF Tubular External Fixator. Berlin: Springer-Verlag, 1985.

10. Weber B. The threaded external fixator. Instrumentation, in: the external fixator AO/ASIF-threaded rod system, SpringerVerlag, 1985, 54-59.

11. Pandey RK, Panda SS. Drilling of bone: A comprehensive review. Journal of Clinical Orthopaedics and Trauma 2013;4(1):15-30.

12. Dell'Oca A. External fixation, in: AO Principles of Fracture Management, Thieme, 2000, 233-247.

13. AO surgery reference website, https://www2.aofoundation.org/wps/portal/surgery.

14. Green S. Principles and Complications of External Fixation. In Skeletal Trauma: Basic Science, Management and Reconstruction (two Volumes) fourth Edition. Elsevier Health Sciences, 2009, 287-322.

15. Labeeu F, Pasuch M, Toussaint P, Van Erps S. External fixation in war traumatology: report from the Rwandese war (October 1, 1990 to August 1, 1993). The Journal of Trauma: Injury, Infection and Critical Care 1996;40(3S):223S-227S.

16. Hamdan TA. Halfway Treatment, Bas J Surg 2014, 2.

17. Vidal J, Melka J. The Double-Frame External Fixator, In: Current Concepts of External Fixation of Fractures, edited by Hans K. Uhthoff, Springer-Verlag, 1982:53-60.

18. Dubravko H, Zarko R, Tomislav T, Dragutin K, Vjenceslav $\mathrm{N}$. External fixation in war trauma management of the extremities-experience from the war in Croatia. J Trauma 1994;37:831-834.

19. Has B, Jovanovic S, Wertheimer B, Mikolasevic I. External fixation as a primary and definitive treatment of open limb fractures, Injury, Elsevier 1995;26(4):245-248.

20. Sakorafas G, Peros G. Principles of war surgery: current concepts and future perspectives, The American Journal of Emergency Medicine 2008;26(4):480-489.

21. Giotakis N, Narayan B. Stability with unilateral external fixation in the tibia. Strategies Trauma Limb Reconstr 2007;2(1):13-20.

22. Topp R, Hayda R, Benedetti G, Twitero T, Carmack DB. The incidence of neurovascular injury during external fixator placement without radiographic assistance for lower extremity diaphyseal fractures: a cadaveric study, J Trauma 2003;55(5):955-8.

23. Coupland R. War wounds of bones and external fixation, Injury 1994;25:211-217.

24. Ronon G, Michaelson M, Waisbrod H. External fixation in war injuries, Injury 1974;6(2):94-98.

25. Clasper J, Phillips S. Early Failure of External Fixation in the Management of War Injuries, JR Army Med Corps 2005; 151:81-86.

26. Weber B. Operative Technique for the Threaded External Fixator, In: Weber BG, Magerl $F$ The external fixator AO/ASIF-Threaded Rod System, Springer-Verlag 1985, 6079.

27. Burny F. Hoftinann External Half Frame Fixation, In: Current Concepts of External Fixation of Fractures, Springer-Verlag 1982, 61-74. 